\title{
HYDROGENOTUNGSTATO COMPLEXES WITH TIN HALOGENURES (IV): INFRARED AND MÖSSBAUER STUDIES
}

\author{
DINORA DE BARROS ${ }^{1}$, MOUHAMADOU SEMBENE BOYE ${ }^{* 2}$, LIBASSE DIOP ${ }^{1}$ \\ ${ }^{1}$ Department of Chemistry, Faculty of Science and Technology, Laboratory of Mineral and \\ Analytical Chemistry (LACHIMIA), Cheikh Anta DIOP University, Dakar, Senegal \\ ${ }^{2}$ Department of Physics Chemistry, Faculty of Sciences and Technologies of Education and \\ Training, Cheikh Anta Diop University, Boulevard Habib Bourguiba, 5036, Fann-Dakar, \\ Senegal
}

\begin{abstract}
Six new hydrogenotungstato adducts and complexes have been synthesized and studied by infrared and Mössbauer techniques. The structures are mainly discrete, the anion behaving as a bidentate -one case- or a monodentate ligand in most cases. When extra hydrogen bonds are considered, supramolecular architectures may be obtained.
\end{abstract}

Keywords: discrete structures, hydrogenotungstato tin (IV) halides adducts, infrared, monodentate hydrogenotungstate ligand, Mössbauer, supramolecular architectures

\section{INTRODUCTION}

$\mathrm{SnX}_{4}(\mathrm{X}=\mathrm{Cl}, \mathrm{Br}, \mathrm{I})$ adducts were studied by Beattie and Rule [1, 2] and by Ohkaku and Nakamoto [3]. If the behavior of sulfate, selenate, oxalate and chromate ions [4-8] has already been the subject of several studies in the context of their association with tin (IV) compounds, organo- and halostannic molybdato and tungstato compounds have been the subject of less research [9] to our knowledge. Within the framework of these studies initiated for several years in our laboratory we were interested in the study of interactions between the quaternary ammonium salts of $\mathrm{WO}_{4} \mathrm{H}_{2}$ and the tin tetrahalides in order to obtain tin (IV) compounds with interesting biological activity. We have thus been able to isolate six new compounds of which infrared and Mössbauer spectroscopic studies have been carried out and presented here.

\section{EXPERIMENTAL SETUP}

\subsection{Synthesis of tungstic acid salts}

$\left(\mathrm{Me}_{4} \mathrm{~N}\right)_{2} \mathrm{WO}_{4} \mathrm{Me}_{4} \mathrm{NHWO}_{4} \cdot 2 \mathrm{H}_{2} \mathrm{O}\left(\mathbf{L}_{\mathbf{1}}\right)$ and $\left(\mathrm{Et}_{4} \mathrm{~N}\right)_{2} \mathrm{WO}_{4} \mathrm{Et}_{4} \mathrm{NHWO}_{4} \cdot 4 \mathrm{H}_{2} \mathrm{O}\left(\mathbf{L}_{2}\right)$ used for synthesis of the studied complexes have been obtained by reacting $\mathrm{H}_{2} \mathrm{WO}_{4}$ acid $97 \%$ (Merck product) with tetramethyl- (10\% water solution Merck product) or tetraethylammonium hydroxide (20\% water solution Merck product) in 1:2 ratio. The solutions have been evaporated in an oven $\left(60{ }^{\circ} \mathrm{C}\right)$ giving powders which are recrystallized from ethanol, washed with ether and then maintained under $\mathrm{P}_{2} \mathrm{O}_{5}$ in a desiccator.

\subsection{Complexes synthesis}

On allowing ethanolic solutions of $\left(\mathbf{L}_{\mathbf{1}}\right)$ and $\mathrm{SnX}_{4}(\mathrm{X}=\mathrm{Cl}, \mathrm{Br})$ in $2: 3$ ratio $\left(\mathbf{A}, \mathbf{B}\right.$, are obtained) while $\left(\mathbf{L}_{2}\right)$ in ethanol reacting with $\mathrm{SnX}_{4}(\mathrm{X}=\mathrm{Cl}, \mathrm{Br})$ in 2:3 or 1:2 ratio gives $(\mathbf{C}, \mathbf{D}, \mathbf{E}$ and $\mathbf{F})$. The various complexes were obtained as white chloro or yellow bromo precipitates stirred for around two hours, filtered and washed with hot

\footnotetext{
* Corresponding author, email: mouhasboye@ hotmail.com

(C) 2019 Alma Mater Publishing House
} 
ethanol. The elemental analyses are reported in Table 1 with the various mixture stoichiometries $(\mathrm{SnX} / \mathrm{salt}) \mathrm{M}$ L.

The analytical data [\% calculated (\% found)], have allowed to suggest the following formulae (Table 1).
$\mathbf{A}=\mathrm{Me}_{4} \mathrm{NHWO}_{4}: \mathrm{SnBr}_{4}$
$\mathbf{D}=\mathrm{Et}_{4} \mathrm{NHWO}_{4} \cdot \mathrm{SnBr}_{5} \mathrm{NEt}_{4}$
$\mathbf{B}=\mathrm{Me}_{4} \mathrm{NHWO}_{4}: \mathrm{SnCl}_{5} \mathrm{NMe}_{4}$
$\mathbf{E}=\left(\mathrm{Et}_{4} \mathrm{NHWO}_{4}\right)_{2} \cdot \mathrm{SnCl}_{3} \mathrm{HWO}_{4}$
$\mathbf{C}=\mathrm{Et}_{4} \mathrm{NHWO}_{4}: \mathrm{SnCl}_{5} \mathrm{NEt}_{4}$
$\mathbf{F}=\left(\mathrm{Et}_{4} \mathrm{NHWO}_{4}\right)_{2} \mathrm{SnBr}_{3} \mathrm{HWO}_{4}$

Table 1. Results of elementary analysis: $\%$ calculated (\% found).

\begin{tabular}{|c|c|c|c|c|c|}
\hline Compounds & $\mathbf{M - L}$ & $\mathbf{\%} \mathbf{C}$ & $\mathbf{\%} \mathbf{H}$ & $\mathbf{\%} \mathbf{~ N}$ & $\mathbf{\%} \mathbf{X}$ \\
\hline$\left(\mathrm{L}_{2}\right)$ & - & $19.65(19.90)$ & $5.19(5.35)$ & $5.73(5.74)$ & - \\
\hline$\left(\mathrm{L}_{1}\right)$ & - & $30.04(29.82)$ & $7.09(7.22)$ & $4.38(4.32)$ & - \\
\hline A & $3-2$ & $9.71(9.98)$ & $3.28(3.14)$ & $1.80(1.90)$ & $42.02(42.44)$ \\
\hline B & $3-2$ & $13.85(13,69)$ & $3.60(3,64)$ & $4.04(4.01)$ & $25.61(26.19)$ \\
\hline C & $3-2$ & $23.85(23.50)$ & $4.96(4.91)$ & $3.47(3.40)$ & $22.05(22.10)$ \\
\hline D & $3-2$ & $18.68(18.41)$ & $3.85(3.67)$ & $3.72(3.60)$ & $38.93(38.50)$ \\
\hline E & $1-2$ & $16.84(16.51)$ & $3.66(3.71)$ & $2.46(2.51)$ & $10.67(11.16)$ \\
\hline F & $1-2$ & $14.06(13.95)$ & $3.15(3.05)$ & $2.05(2.01)$ & $17.56(18.21)$ \\
\hline
\end{tabular}

$\mathrm{M}-\mathrm{L}=$ metal-ligand

The elemental analyses have been performed at the Service Central d'Analyses-CNRS- Vernaison-France or at the Microanalyses Laboratory of the University of Padua (Italy). The infrared spectra were recorded at the University of Padova (Italy) at room temperature using a Perkin Elmer 580 spectrophotometer $\left(4000-200 \mathrm{~cm}^{-1}\right)$ and a Nicolet 5300 type Fourier transform infrared spectrophotometer $\left(600-50 \mathrm{~cm}^{-1}\right)$ as a suspension of the powders in Nujol. The faces used are cesium iodide or polyethylene for low frequencies. Infrared abbreviations: (vs) very strong; (s) strong; (m) medium; (vw) very weak; (w) weak; (sh) shoulder. Mössbauer spectra were recorded using a source of $\mathrm{Ca}^{119} \mathrm{SnO}_{3}$ in constant acceleration; the sample being maintained between $80 \mathrm{~K}$ and $100 \mathrm{~K}$. An accurate program based on the least square's method allows to find by calculation the experimental spectrum and to make a deduction of the different parameters $(\delta$ : isomeric shift; $\Delta \mathrm{E}$ : quadrupole splitting; $\Gamma$ : full width at half-height).

\section{RESULTS AND DISCUSSION}

In Tables 2 and 3, the main infrared and Mössbauer data of the six compounds are reported (the spectral quality did not allow to locate $v \mathrm{OH}$ which appears very weakly in infrared when the $-\mathrm{OH}$ group is not involved in a hydrogen bond).

Table 2. Frequencies in $\mathrm{cm}^{-1}$ of the main IR bands of the complexes.

\begin{tabular}{|c|c|c|c|c|}
\hline Attributions $\rightarrow$ & $\mathrm{VWO}_{4}$ & $\mathrm{SWO}_{4}$ & $V_{\text {as }} M-X$ & VM-O \\
\hline \multicolumn{5}{|l|}{ Compounds $\downarrow$} \\
\hline $\mathbf{A}$ & $\begin{array}{c}982 \mathrm{~m} \\
890 \mathrm{sh} \\
815 \mathrm{~s}\end{array}$ & $\begin{array}{l}586 \mathrm{~m} \\
444 \mathrm{~m} \\
355 \mathrm{~m}\end{array}$ & $210 \mathrm{vs}$ & $280 \mathrm{w}$ \\
\hline B & $\begin{array}{c}980 \mathrm{~m} \\
890 \mathrm{~m} \\
815 \mathrm{~s}\end{array}$ & $\begin{array}{l}650 \mathrm{sh} \\
580 \mathrm{~m} \\
445 \mathrm{w} \\
395 \mathrm{sh} \\
350 \mathrm{sh}\end{array}$ & $300 \mathrm{vs}$ & - \\
\hline $\mathbf{C}$ & $\begin{array}{c}983 \mathrm{~s} \\
891 \mathrm{w} \\
814 \mathrm{vs}\end{array}$ & $\begin{array}{l}584 \mathrm{~m} \\
445 \mathrm{~m}\end{array}$ & 295 vs & - \\
\hline D & $\begin{array}{l}983 \mathrm{~s} \\
880 \mathrm{w} \\
812 \mathrm{vs}\end{array}$ & $\begin{array}{l}584 \mathrm{~m} \\
445 \mathrm{~m} \\
370 \mathrm{w} \\
350 \mathrm{w} \\
280 \mathrm{w}\end{array}$ & $210 \mathrm{vs}$ & $280 \mathrm{w}$ \\
\hline
\end{tabular}




\begin{tabular}{|c|c|c|c|c|}
\hline \multirow{3}{*}{$\mathbf{E}$} & $983 \mathrm{~m}$ & $586 \mathrm{~m}$ & $225 \mathrm{vs}$ & - \\
& $893 \mathrm{w}$ & $445 \mathrm{~m}$ & $370 \mathrm{~s}$ & \\
\hline \multirow{3}{*}{ F } & $980 \mathrm{w}$ & $586 \mathrm{w}$ & & $290 \mathrm{~s}$ \\
& $960 \mathrm{~m}$ & $445 \mathrm{~m}$ & $210 \mathrm{~s}$ & \\
& $962 \mathrm{~m}$ & $366 \mathrm{w}$ & & \\
\hline
\end{tabular}

$v=$ stretching vibration; $v_{\mathrm{as}}=$ antisymmetric stretching vibration; $\delta=$ deformation vibration.

Table 3. Mössbauer parameters of complexes

\begin{tabular}{|c|l|l|l|l|l|l|}
\hline Compounds $\rightarrow$ & A & B & C & D & E & F \\
\hline$\delta\left(\mathrm{mm} \cdot \mathrm{s}^{-1}\right)$ & 0.52 & 0.37 & 0.37 & 0.58 & 0.13 & 0.21 \\
\hline$\Delta \mathrm{E}\left(\mathrm{mm} \cdot \mathrm{s}^{-1}\right)$ & 0.66 & 0.44 & 0.44 & 0.54 & 0.56 & 0.60 \\
\hline$\Gamma\left(\mathrm{mm} \cdot \mathrm{s}^{-1}\right)$ & 0.99 & 0.97 & 0.97 & 0.99 & 0.94 & 1.05 \\
\hline
\end{tabular}

For $\mathrm{Me}_{4} \mathrm{NHWO}_{4} \mathrm{SnBr}_{4}(\mathrm{~A})$, the important quadrupole splitting of $\mathrm{SnBr}_{4}$ and the sharpness of the band assigned to $\mathrm{vSnBr}_{4}$ (vibration Eu type according to the Group Theory) allow to conclude to a $\mathrm{SnBr}_{4} \mathrm{molecule}_{\mathrm{f}}$ of $\mathrm{D}_{4} \mathrm{~h}$ symmetry (transcoordination and centrosymmetry according to Group Theory): the proposed structure is an infinite chain with transcoordinated $\mathrm{SnBr}_{4}$ molecules, the hydrogenotungstate being a bi-unidentate ligand (Figure 1).

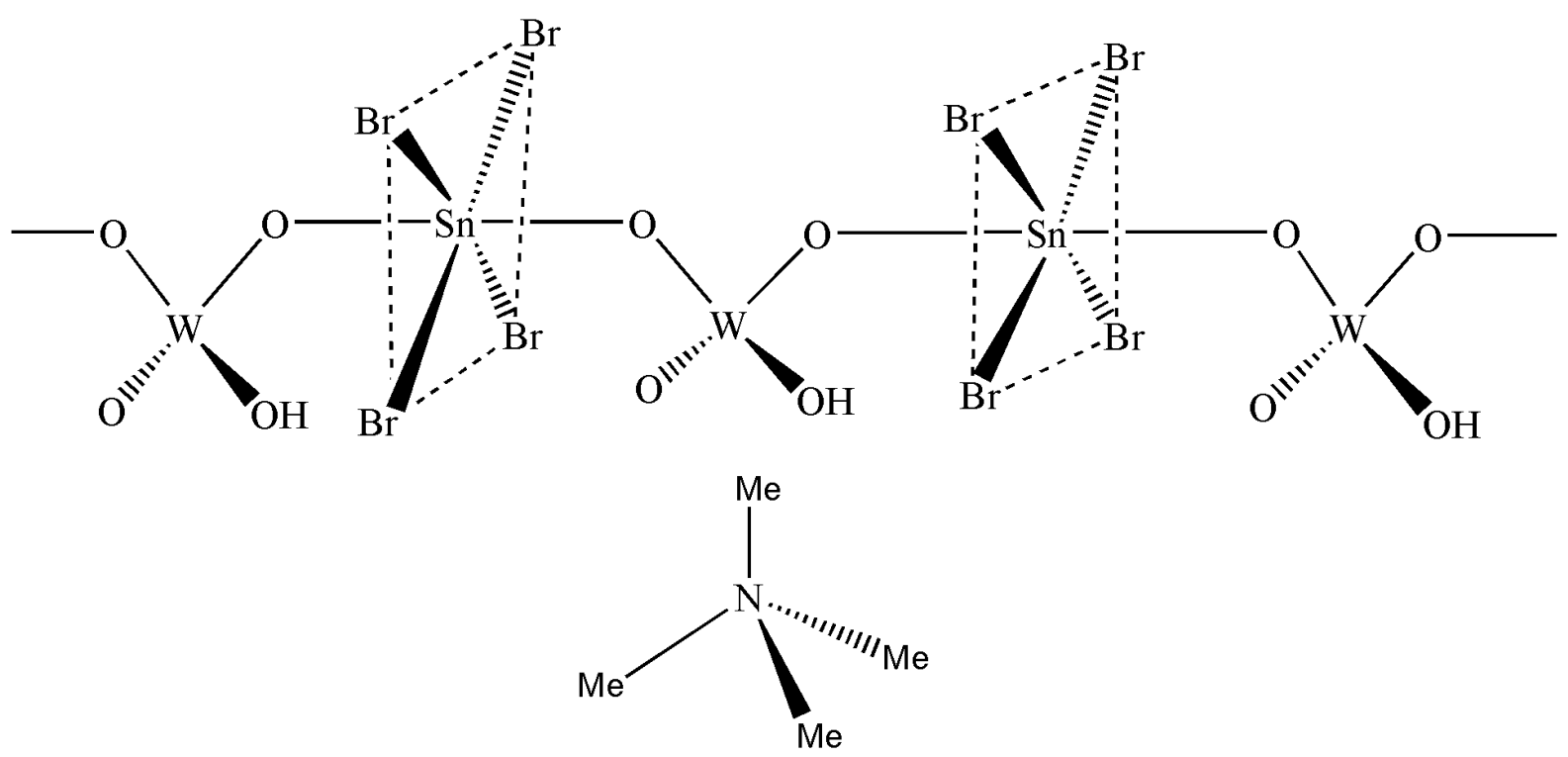

Fig. 1. Proposed structure for the compound A.

For $\mathrm{R}_{4} \mathrm{NHWO}_{4} \mathrm{SnX}_{5} \mathrm{NR}_{4}(\mathbf{B}, \mathbf{C}$ and $\mathbf{D})$; $(\mathrm{R}=\mathrm{Me}$, Et and $\mathrm{X}=\mathrm{Cl}, \mathrm{Br})$, the isomeric shifts values are similar to those of the literature- the increase of the isomeric shift values when going from chlorine to bromine is respected [10]. The proposed structure is a discrete structure with a monodentate hydrogenotungstate (Figure 2).

The formulae difference between $\mathrm{Me}_{4} \mathrm{NHWO}_{4} \mathrm{SnBr}_{4}$ and $\mathrm{Me}_{4} \mathrm{NHWO}_{4}: \mathrm{SnCl}_{5} \mathrm{NMe}_{4}$ compounds can be due to the size of the halides since $\left[\mathrm{HWO}_{4} \cdot \mathrm{SnCl}_{4}\right]^{-}$and $\left[\mathrm{HWO}_{4}: \mathrm{SnCl}_{5}\right]^{2-}$ complexes anions could be obtained and not $\left[\mathrm{HWO}_{4} \mathrm{SnBr}_{5}\right]^{2-}$. In fact, we know that the ratio (cation radius/anion radius) determines the type of crystal arrangement and the global environment around the metallic center. So, we see that with the tetraethylammonium ion, we find in the chloro complexes, as in the bromo complex, $\left[\mathrm{HWO}_{4}: \mathrm{SnX}\right]^{2-}$ complex anion whereas with smaller cation (tetramethylammonium ion) it was not possible to obtain $\mathrm{Me}_{4} \mathrm{NHWO}_{4}: \mathrm{SnBr}_{5} \mathrm{NMe}_{4}$. 


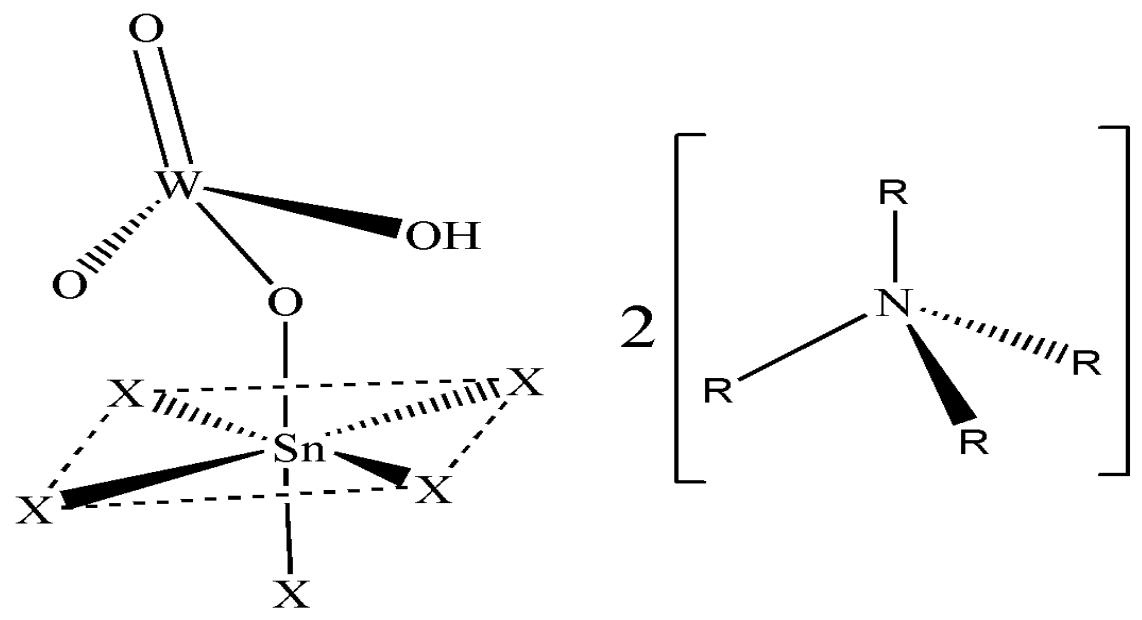

$(\mathrm{X}=\mathrm{Cl}, \mathrm{Br} ; \mathrm{R}=\mathrm{Me}, \mathrm{Et})$

Fig. 2. Proposed structure for compounds $\mathbf{B}, \mathbf{C}$ and $\mathbf{D}$.

For $\left(\mathrm{Et}_{4} \mathrm{NHWO}_{4}\right)_{2} \mathrm{SnX}_{3} \mathrm{HWO}_{4}(\mathbf{E}$ and $\mathbf{F}) ;(\mathrm{X}=\mathrm{Cl}, \mathrm{Br})$, with an excess of ligand it was possible to substitute a halogen of $\mathrm{SnX}_{4}$ by $\mathrm{HWO}^{-}$to obtain $\left(\mathrm{SnX}_{3} \mathrm{HWO}_{4}\right)$ which then reacts with two hydrogenotungstate ions to give the complexes $\mathbf{E}$ and $\mathbf{F}$.

The values of the isomeric shift confirm the expected increase when going from chlorine to bromine [10]. The proposed structure is discrete, the environment around the tin being octahedral (Figure 3) (we note that $\left[\mathrm{SnX}_{3}\left(\mathrm{HWO}_{4}\right)_{3}\right]^{2-}$ complex anion could only be obtained with the tetraethylammonium ion and not with the tetramethylammonium ion).

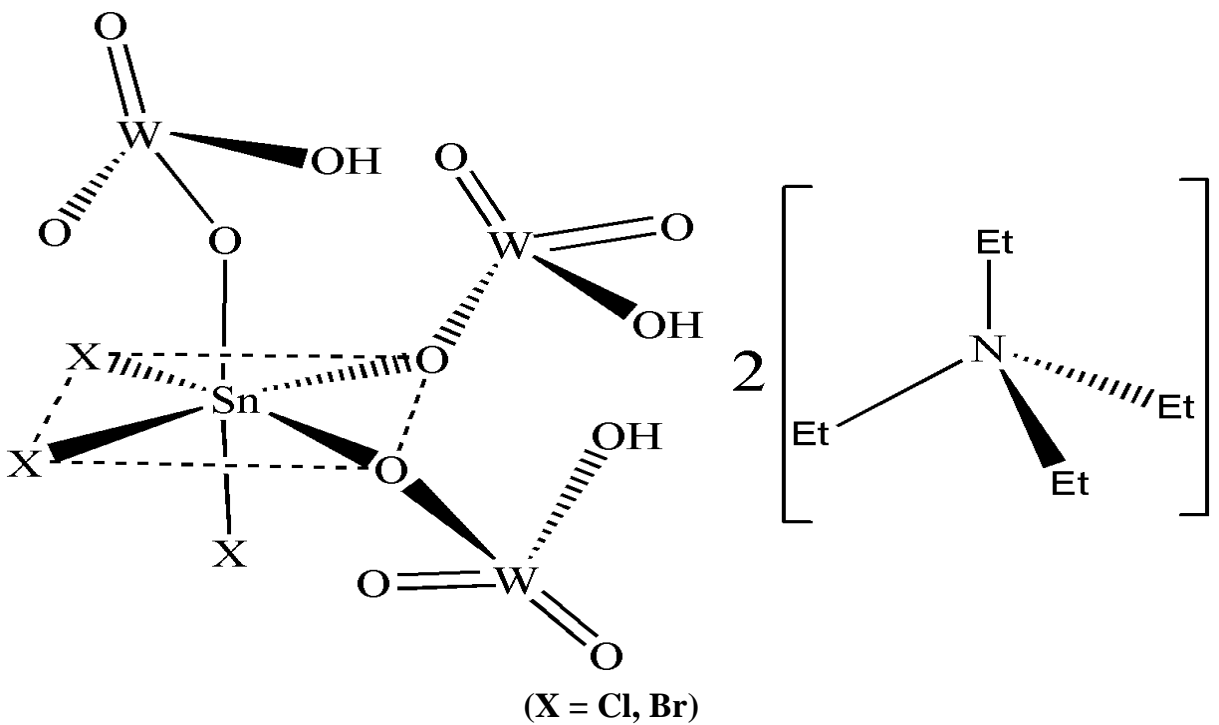

Fig. 3. Proposed structure for compounds $\mathbf{E}$ and $\mathbf{F}$.

N.B.: In all the proposed structures, the -OH groups, when considered involved in hydrogen bonding, supramolecular architectures may be obtained.

\section{CONCLUSIONS}

With the hydrogenotungstate, tin (IV) halides form mononuclear complexes of mostly discrete structure (five out of six), the anion generally behaving as a monodentate. As in the case of organotin, the hydrogenotungstate was found to be in the starting acidic salt, the chemical entity having the strongest coordinating power. The size of the antagonist cation appears to be decisive in the stoichiometry of the complex ion obtained. 


\section{ACKNOWLEDGEMENTS}

We thank Professor M. Vidali and Professor U. Russo (University of Padova - Italy) for equipment support and for performing part of the elemental analysis.

\section{REFERENCES}

[1] Beattie, I.R., Rule, L., The Raman spectra of some adducts of tin tetrachloride, Journal of the Chemical Society, no. 0, 1965, p. 2995-2996.

[2] Beattie, I.R., Rule, L., cis-trans-Isomerism in octahedral $\mathrm{SnCl}_{4} \mathrm{~L}_{2}$ studied by infrared spectroscopy in the coesium bromide region, Journal of the Chemical Society, no. 0, 1964, p. 3267-3273.

[3] Ohkaku, N., Nakamoto, K., Metal isotope effect on metal-liquid vibrations. X. Far-infrared spectra of trans adducts of tin (IV) tetrahalide with unidentate ligands, Inorganic Chemistry, vol. 12, no. 10, 1973, p. 2440-2446.

[4] Kokunov, Yu.V., Detkov, D.G., Gorbunova, Y.E., Ershova, M.M., Mikhailov, Yu.N., Tin(II) sulfato fluoro mixed complexes: The synthesis and structure of $\mathrm{M}\left[\mathrm{SnF}\left(\mathrm{SO}_{4}\right)\right]\left(\mathrm{M}=\mathrm{NH}_{4}, \mathrm{~K}\right)$, Russian Journal of Inorganic Chemistry, vol. 46, no. 2, 2001, p. 217-221.

[5] Kokunov, Yu.V., Gorbunova, Y.E., Detkov, D.G., Tin(II) oxalate and oxalate fluoride polymeric compounds: Synthesis and crystal structure of $\left(\mathrm{H}_{3} \mathrm{~N}\left(\mathrm{CH}_{2}\right)_{2} \mathrm{NH}_{3}\right) 0.5\left[\mathrm{SnF}\left(\mathrm{C}_{2} \mathrm{O}_{4}\right)\right] \cdot \mathrm{H}_{2} \mathrm{O}$ and $\left(\mathrm{H}_{3} \mathrm{~N}\right.$ $\left.\left(\mathrm{CH}_{2}\right)_{2} \mathrm{NH}_{3}\right)\left[\mathrm{Sn}_{2}\left(\mathrm{C}_{2} \mathrm{O}_{4}\right)_{3}\right] \cdot 0.5 \mathrm{H}_{2} \mathrm{O}$, Russian Journal of Inorganic Chemistry, vol. 49, no. 7, 2004, p. 1000-1006.

[6] Diallo, W., Diop, L., Plasseraud, L., Cattey, H., [n- $\left.\mathrm{Bu}_{2} \mathrm{NH}_{2}\right]_{3}\left[\mathrm{SnPh}_{3}\left(\mathrm{SeO}_{4}\right)_{2}\right]$ : the first triorganotin(IV) complex with terminally coordinated selenato ligands, Main Group Metal Chemistry, vol. 37, no. 3-4, 2014, p. 107-112.

[7] Seck, S.M.S., Diop, L., Lorenzo, S., New organotin (IV) oxalato adduts: synthesis and spectroscopic studies, Scientific Study and Research-Chemistry and Chemical Engineering, Biotechnology, Food Industry, vol. 12, no. 2, 2012, p. 263-270.

[8] Diallo, W., Touré, A., Diop, C.A.K., Sidibe, M., Some new oxalato and sulfato $\mathrm{SnR}_{3}(\mathrm{R}=\mathrm{Me}, \mathrm{Ph})$ and $\mathrm{SnR}_{2}{ }_{2} \mathrm{Cl}\left(\mathrm{R}^{\prime}=\mathrm{Ph}, \mathrm{Bu}\right)$ residues containing derivatives and complexes: Synthesis, infrared, NMR and Mössbauer studies, International Journal of Advanced Research, vol. 6, no. 2, 2018, p. 861-870.

[9] Groom, C.R., Bruno, I.J., Lightfoot, M.P., Ward, S.C., The cambridge structural database, Acta Crystallographica Section B: Structural Science, Crystal Engineering and Materials, vol. 72, no. 2, 2016, p. 171179.

[10] Tudela, D., Fernández, V., Tornero, J., Mössbauer study of the cis-trans isomers of tin (IV) complexes. Some considerations about the sign of the electric-field gradient, Journal of the Chemical Society, Dalton Transactions, no. 7, 1985, p. 1281-1284. 